\section{Summary of: Specialists' management decisions and attitudes towards mucositis and peri-implantitis}

\author{
N. Mattheos, ${ }^{1}$ S. Collier ${ }^{2}$ and A. D. Walmsley ${ }^{3}$
}

FULL PAPER DETAILS

${ }^{1 *}$ School of Dentistry and Oral Health, Griffith University, 16-30 High Street, QLD 4215, Gold Coast, Australia; ${ }^{2}$ University of Birmingham, School of Dentistry, St Chad's Queensway, Birmingham, B4 6NN; 3University of Birmingham, School of Dentistry, St Chad's Queensway, Birmingham, B4 6NN ${ }^{*}$ Correspondence to: Nikos Mattheos

Email:nikos@mattheos.net; Tel: +0061433193688

Online article number E1

Refereed Paper - accepted 9 Spetember 2011

DOI: 10.1038/sj.bdj.2012.1

${ }^{\circ}$ British Dental Journal 2012; 212: E1

\begin{abstract}
Background Pathology of the peri-implant tissues, namely peri-implant mucositis and peri-implantitis are conditions that are often encountered and can threaten the long term survival of the implants. Aim This study aimed to compare the attitudes of registered specialists in periodontology in Australia and the UK towards aetiology, prevalence, diagnosis and management of mucositis and peri-implantitis. Methods A validated questionnaire was used and the sample consisted of UK and Australian specialists. Results There were differences in the demographics of specialists in the two countries, with the Australian specialists being significantly younger. Most specialists in both countries identified the prevalence of peri-implant pathology between 0-25\%. Although there was agreement as to the role of plaque in the aetiopathogenesis of the diseases, UK specialists were more likely to include adverse loading and smoking as etiological factors. There were significant differences in the management of the disease between the groups, including the use of mouth rinses, local and systemic antibiotics. Australians were more likely to use systemic antibiotics than in the UK. Conclusions The results suggested that differences in professional demographics, educational resources and market factors, and the absence of consensus treatment standards can significantly affect the treatment modalities patients finally receive.
\end{abstract}

\section{EDITOR'S SUMMARY}

We know a lot about implants but, importantly, we still have a lot to learn about them as well.

The interface of biologic and technologic has a literal as well as a philosophic meaning here and in much the same way as it is not possible to place an implant until you have performed an extraction, so it is not possible to predict subsequent pathology until you have explained its causality.

Mucositis and peri-implantitis are conditions as new as implants themselves and by setting out to establish differences between clinicians in the UK and Australia in relation to their opinions on aetiology, prevalence, diagnosis and management, this study inevitably bordered on other issues such as training, professional organisation and market forces. What has emerged is a lack of consistency in management, especially in the current absence of any consensus treatment standards with potential consequences to the effectiveness of individually applied measures.

The specialists studied had broadly the same scientific backgrounds but the interpretation and consequent attitudes developed as a result showed some marked differences especially in prescribing patterns and use of instrumentation. What gives this diversity greater significance is that if this variation occurs in relatively similarly trained experts, how much greater might be the range in general dental practitioners who are, arguably, the clinicians who are going to have to manage these conditions on a more regular and sustained basis?

With the increasing move towards regarding oral health maintenance as a shared responsibility between dental professional and patient there is also an imperative to be able to explain the aetiology and management succinctly to the patient if they are to be able to participate in the process. This again begs the need for greater research and understanding as well as evidence-based answers to the optimal treatment choices. The concern must be that patients who have implants, except for those who have lost teeth through trauma, have a history of less than ideal oral health and an absence of knowledge may prove to be a significant long-term handicap to successful retention of these otherwise much vaunted appliances.

The full paper can be accessed from the $B D J$ website (www.bdj.co.uk), under 'Research' in the table of contents for Volume 212 issue 1.

Stephen Hancocks Editor-in-Chief

DOI: 10.1038/sj.bdj.2012.26 
TO ACCESS THE BDJ WEBSITE TO READ THE FULL PAPER:

- BDA Members should go to www.bda.org.

- Click the 'login' button on the right-hand side and enter your BDA login details.

- Once you have logged in click the 'BDJ' tab to transfer to the BDJ website with full access.

IF YOUR LOGIN DETAILS DO NOT WORK:

- Get a password reminder: go to www.bda.org, click the login button on the right-hand side and then click the forgotten password link.

- Use a recommended browser: we recommend Microsoft Internet Explorer or Mozilla Firefox.

- Ensure that the security settings on your browser are set to recommended levels.

IF YOU HAVE NOT YET SIGNED UP TO USE THE BDA WEBSITE:

- Go to www.bda.org/getstarted for information on how to start using the BDA website.
IN BRIEF

- Indicates the lack of a universal approach to the management of peri-implant diseases in both Australia and the UK.

- While specialists reported seeing periimplant pathology in no greater than $25 \%$ of their patients, they estimated the prevalence in the general population to be significantly higher.

- Local antibiotics are more popular among UK specialists, with systemic antibiotics more frequently used in Australia.

\section{COMMENTARY}

Today, the use of dental implants in everyday clinical practice is a valid treatment option for the replacement of missing teeth. This is a result of the rigorous research conducted in the field of implant dentistry which provided robust clinical protocols based on the biologic principles of osseointegration. It is interesting though to notice that research in relation to the biologic complications of dental implants, even though increasing, still presents with a number of open clinically related questions.

The aim of this study was to compare the attitude of Specialists in Periodontics in the UK and Australia towards prevalence, diagnosis and management of peri-implant mucositis and periimplantitis. The findings of this study clearly indicate that, in both countries, there is a significant proportion of patients presenting with the above named complications. However, it is also clear that even though systematic reviews in aetiology and pathogenesis of biologic complications have recently been produced by consensus conferences of the EFP (European Federation of Periodontology) there is still lack of complete agreement between specialists of the two countries in terms of true aetiologic or modifying factors. At the same time, the lack of clear guidelines in terms of effective, long-term treatment of the biologic complications (especially peri-implantitis) but also of effective maintenance schemes raises an important issue in relation to the optimal standards of care provided to the patients. It is also critical to emphasise that the authors indicate that the findings of the study have 'direct implications for the education process of the specialists' which is an issue associated with the content of postgraduate education and relevant competencies that has been discussed in length during the 1st Workshop in Implant Dentistry of ADEE., ${ }^{1,2}$

In conclusion, the differences presented in this study in both opinions and attitudes as well as management of peri-implant pathology by specialists between UK and Australia clearly emphasises the need for further appropriately designed per-clinical and clinical research in this area which will result in universally accepted, evidence based guidelines allowing the specialists to provide the optimal care to the patients.

\section{N. Donos}

Head \& Chair of Periodontology,

UCL Eastman Dental Institute

1. Mattheos N, Albrektsson T, Buser D et al. Teaching and assessment of implant dentistry in undergraduate and postgraduate education: a European consensus. Eur J Dent Educ 2009; 13(Suppl 1): 11-17.

2. Donos N, Mardas N, Buser D; 1st European Consensus Workshop in Implant Dentistry University Education. An outline of competencies and the appropriate postgraduate educational pathways in implant dentistry. Eur J Dent Educ 2009; 13(Suppl 1): 45-54.

\section{AUTHOR QUESTIONS AND ANSWERS}

1. Why did you undertake this research? Peri-implant tissue pathology is a relatively new disease entity. Consequently we currently lack the evidence level and strong consensus guidelines with regards to the management of periimplant mucosits and peri-implantitis. Therefore, we initiated this study aiming to investigate the current perceptions and strategies followed by specialists in the absence of a 'gold standard'. The UK and Australia offer an interesting basis for comparison, as the dental education structures and the education of specialists are very similar; certain differences in the practice environment, however, might have significant implications in the treatment strategies adopted.

\section{What would you like to do next in this} area to follow on from this work?

The results of this work indicate the need for further work towards improving the evidence base and standardisation of the management of peri-implant pathology. As the majority of implant patients today are maintained by general practitioners rather than specialists, we would like to expand the study to investigate how general practitioners diagnose and manage peri-implant pathology. Empirical evidence would suggest the diversity to be far greater in this group. At a later stage, we aspire to identify areas of wider diversity and consequently point out the directions where stronger evidence must be acquired towards the development of evidence-based, widely applicable treatment strategies. 